Original Article

\title{
Prevalence of Primary Headache in Association with Age, Sex, Obesity and Hypertension among patients received at OPD of Liaquat University Hospital, Hyderabad / Jamshoro
}

\author{
Santosh Kumar, Shafaq Nazia, , Suhail Ahmed Almani, Manzoor Lakhair, \\ Muhammad Iqbal Shah, Zubair Suhail
}

ABSTRACT

AIM AND OBJECTIVE: To determine the association of primary headache with age, sex, obesity and hypertension among patients received at medical Out-patient-department of Liaquat University Hospital, Hyderabad / Jamshoro.

STUDY DESIGN: It is a cross-sectional study conducted at Liaquat University Hospital Out-Patient Department, Hyderabad / Jamshoro, to determine the prevalence of primary headache in association with sex, age, obesity and hypertension.

PLACE AND DURATION OF STUDY: Out-Patient-Department of medicine in Liaquat University Hospital, Hyderabad / Jamshoro from $1^{\text {st }}$ January 2015 to $1^{\text {st }}$ June 2015

METHODOLOGY: This cross-sectional study was conducted with 200 patients (both male and female) from different age groups received in Out-Patient-Department of Liaquat University Hospital, Hyderabad. SPSS 20 version was used for analysis and results. Proforma questionnaires were used for patients including bio-data, history, blood pressure and BMI.

Inclusion criteria: All adult patients, both males and females, over the age of 18 years, with presenting complaint of headache were included in the study after taking proper consent. Proper history taking, vital signs, neurological examination, eye examination, BMI, and random blood sugar level were performed.

Exclusion criteria: Patients having stroke, hypoglycemia (blood sugar $<60 \mathrm{mg} / \mathrm{dl}$ ), diabetic ketoacidosis, intracranial hypertension, eye problem, and Chronic Liver Disease were excluded from this study.

RESULTS: Out of a total number of 200 patients, $60 \%$ were female and $39 \%$ were male, while $1 \%$ was dropout during follow-up. Most of the patients were between the ages of 30-60 years. Our study determines $\mathbf{8 6} \%$ of patients have primary headache with normal blood pressure (normal BP $\mathbf{8 8 \%}$ ) and $13 \%$ have secondary headache mostly caused by hypertension (BP 10\%), 1\% patients was dropout during follow-up from study. Out of 200 patients, $\mathbf{4 8} \%$ were found to have a normal BMI (body mass index), whereas $39 \%$ were over weight and $11 \%$ had obesity and $2 \%$ came under category of morbid obesity.

CONCLUSION: This study result determined that among the patients received at medical Out-Patient Department of Liaquat University Hospital, Hyderabad / Jamshoro, primary headache is more common in young females who have an increased body mass index and normal blood pressure. So it is prudent to spread awareness through media campaigns, seminars, and workshops etc, regarding prevention and proper treatment of primary headache in such patients.

KEY WORDS: primary headache, sex, blood pressure (BP), body mass index, out patients department (OPD).

This article may be cited as: Kumar S, Nazia S, Almani SA, Lakhair M, Shah MI, Suhail Z. Prevalence of Primary Headache in Association with Age, Sex, Obesity and Hypertension among patients received at OPD of Liaquat University Hospital, Hyderabad / Jamshoro. J Liaquat Uni Med Health Sci. 2017;16(02):103-7. doi: 10.22442/jlumhs.171620515

\section{INTRODUCTION}

Headache is very common issue / problem in private or government sector hospital of Pakistan. Holland $S$ et $\mathrm{al}^{8}$ expressed that more than 13 million population of America have headache. Primary headache are more common than secondary headache in globe. Headache is most common presentation in out patient department of medical ward or neurology in all over the world. It is caused by pain sensitive area of brain 
parenchyma, meninges, eyes, ear, nose, sinuses, mucous membrane, periosteum of cranium etc. It is classified as primary headache or idiopathic and secondary headache means due to some disease. However, the prevalence of life threatening headache is very low in emergency department of hospital. Headache is such a common complaint that occurs due to several underlying conditions that makes its proper evaluation very difficult ${ }^{2}$. In addition, obesity is more prevalent in women as compared to men ${ }^{2}$. Worldwide burden of primary headache is very large but a lot of knowledge still needs to be sought in this regard. In different studies of headache literature shows that familial and genetic relationship in families with increased incidence of headache $e^{2,3}$. The resultant evolution of this questionnaire was reviewed by an expert consensus group drawn from all world regions. The final output was the Headache-Attributed Restriction, Disability, Social Handicap and Impaired Participation questionnaire, designed for application by trained lay interviewers ${ }^{2}$. The recent onset of severe headache in previously healthy individuals is more likely to be due to life threatening conditions such as subarachnoid hemorrhage or meningitis and warrants further investigations stated in Steiner TJ et al study ${ }^{10}$. Similarly, progressive headache in middle aged or elderly that disturbs daily ordinary activities and is associated with neurological disability, usually requires computerized tomographic scan and magnetic resonance imaging. Relation of obesity with headache show that a large number of patients complaining of headache have a normal body mass index as compared to those who are overweight ${ }^{8}$. Obesity and morbid obesity are not related to migraine episodes which differ from worldwide studies. Different articles of international neurology and headache journals expressed that mortality or morbidity are related headache with secondary causes like cerebral vascular accident, sub arachnoids hemorrhage, intracranial hypertension, familial or genetically problem runs in family of different population of world ${ }^{8-}$ 11. In India the burden of primary headache related with sex, gender, obesity and hypertension are more prevalent then other cause, which leads socioeconomically effect all over society ${ }^{12}$.

\section{METHODOLOGY}

It is a cross-sectional study conducted with 200 patients (both male and female) belongs to different age groups, received in Out-Patient-Department of Liaquat University Hospital, Hyderabad / Jamshoro. Duration of study was from $1^{\text {st }}$ January to $1^{\text {st }}$ June 2015. Proforma questionnaires were used for patients bio-data, history, blood pressure, BMI and random blood sugar. Data was then analyzed using statistical package for social sciences version 20. Frequencies and percentages were calculated for categorical data like mean, mode, average and confidence interval.

\section{RESULTS}

Out of 200 patients, $60 \%$ were female and $39 \%$ were male, and $1 \%$ patients were dropout on follow-up. Out of total 200 patients, $86 \%$ of patients have primary headache with normal blood pressure (normal BP $88 \%$ ) and $13 \%$ have secondary headache mostly caused by hypertension (BP 10\%), 1\% patients are dropout on follow-up (Table I and Bar Chart No. 1). Out of 200 patients, $48 \%$ had normal BMI (body mass index), 39\% were over weight and $11 \%$ had obesity and $2 \%$ had morbid obesity (Bar Chart No. 2).

\section{TABLE I:}

SHOWING DIFFERENT SEX OF PATIENTS

\begin{tabular}{|c|c|c|c|c|}
\hline & & Frequency & Percent & $\begin{array}{l}\text { Valid } \\
\text { Percent }\end{array}$ \\
\hline \multirow{3}{*}{ Valid } & Male & 78 & 39.0 & 39.4 \\
\hline & Female & 120 & 60.0 & 60.6 \\
\hline & Total & 198 & 99.0 & 100.0 \\
\hline \multicolumn{2}{|r|}{ Dropout } & 2 & 1.0 & \\
\hline \multicolumn{2}{|r|}{ Total } & 200 & 100 & \\
\hline
\end{tabular}

BAR CHART NO.1: NORMAL BP, GRADE 1 BP, GRADE 2 BP

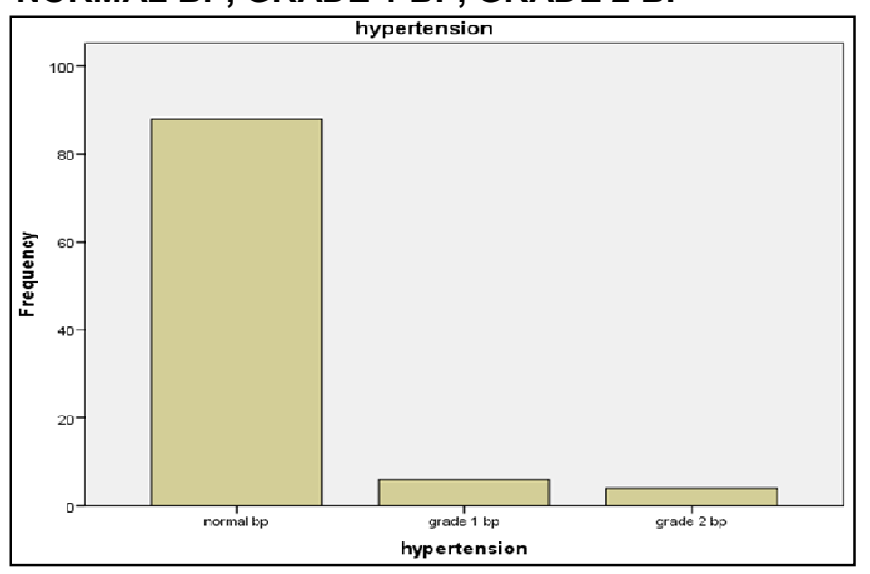




\section{PIE CHART NO. 1: DIFFERENT PERCENTAGE OF HEADACHE}

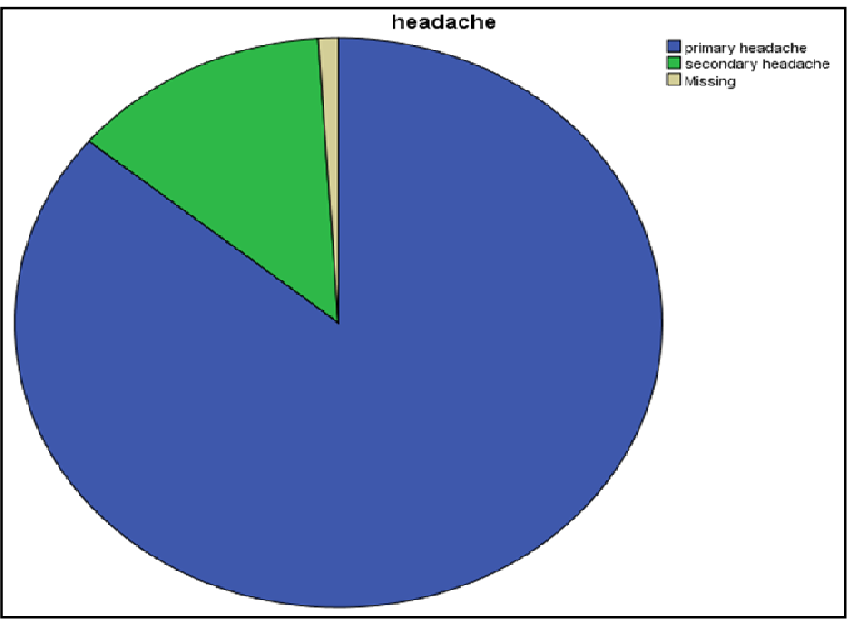

BAR CHART NO. 2: DIFFERENT BMI IN PATIENTS

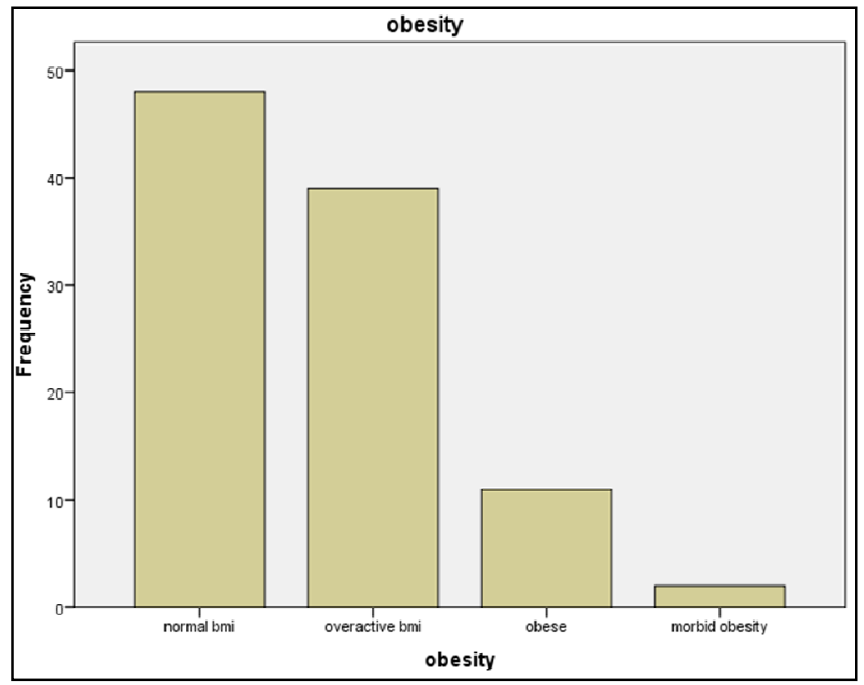

\section{DISCUSSION}

Headache due to migraine or tension, described as pulsating or throbbing pain, cause tightness or pressure feeling in patients. More than $80 \%$ of patients with cephalic pain are labeled as idiopathic or primary as no cause is recognized. On the other hand, less than $20 \%$ headaches are secondary. Headache is a very common complaint in medical Out-PatientDepartment of Liaquat University Hospital, Hyderabad/Jamshoro. Lancinating pain suggests a neurotic pain ocular or ice-pick like pain in primary headache or cluster headache. A dull steady pain associated with persistent vomiting favors intracranial lesions. Several studies were done in United States show that one in every fourth household includes someone with primary headache, most likely migraine ${ }^{13}$. A small percentage of people with cephalic pain between 20 to 40 years male or female young relieved sign and symptoms through non steroidal anti inflammatory drugs (NSAIDS). Even so, such medications may be considered in special situations where simple pain relievers are ineffective or contraindicated (e.g. women in the third trimester of pregnancy, patients with ulcers, severe kidney failure or liver failure) ${ }^{14}$. Primary headache disorders are a major public-health problem globally and possibly more so in low and middle income countries. No methodologically sound study of prevalence and burden of headache in the adult Indian population had been published previously. Study was conducted in sub area of India with door-to-door cold-calling survey in urban and rural areas in and around Bangalore, Karnataka State. From 2714 households contacted, 2514 biologically unrelated individuals were eligible for the survey and 2329 (92.9\%) participated 1103 (48\%) rural; 1226 (52 \%) urban; 1141 (49 \%) male; 1188 (51\%) female; mean age 38.0 years. The different literature article of international headache stated that to manage headache with proper history, examination of nervous system, eye and sinuses or ear etc with laboratory investigation and preplanned questionnaires, by which we should differentiate primary form secondary headache ${ }^{15}$.

However, several studies have reported a different prevalence of headache types, which might be due to different methodologies used as well as cultural and population characteristics of the studied patients. In this study (Pie chart No. 1) shows that primary headaches are more common in our society and secondary headache are less than $16 \%$ in local OPD of LUH, Hyderabad ${ }^{16}$ Recent sinusitis or hay fever, dental surgery, head injury, migraine are exacerbated by emotional stress, fatigue, food containing nitrites or tyramine or the menstrual periods, Alcohol may precipitate cluster headache. Many studied in United States of America where primary headache found in obese patients ${ }^{17,18}$, another study conducted in china where primary headache is seen in non obese person $^{19-20}$.

In a retrospective study in Pakistan, it was shown that migraine headache is the most common type, with a prevalence of $92 \%$ in our population ${ }^{21}$.

\section{CONCLUSION}

This study results determines that incidence of 
primary headache is more common among patients, so for that we should have proper approach to educate and counsel local population on how to eradicate risk factors and aggravating agents. So it is important to carry out mega trials, awareness programs, media campaigns, seminars, and workshops etc regarding prevention and treatment of primary headache in local population of country.

\section{REFERENCE}

1. Silberstein SD, Holland S, Freitag $F$, et al. Evidence-based guideline update: Pharmacologic treatment for episodic migraine prevention In adults: report of the Quality Standards Subcommittee of the American Academy of Neurology and the American Headache Society. Neurology. 2012; 78(17):1337-45.

2. Lipton RB, Bigal ME, Diamond $M$, et al. Migraine prevalence, disease burden, and the need for preventive therapy. Neurology. 2007; 68(5):343-349.

3. Demarin V, Vukovic V, Lovrencic- Huzjan A, et al. Evidence based guidelines for the treatment of primary headaches. Acta Med Croatica. 2008; 62:99-136.

4. Ravishankar K, Chakravarty A, Chowdhury D, Shukla R, Singh S. Guidelines on the diagnosis and the current management of headache and related disorders. Ann Indian Acad Neurol. 2011;14(Suppl. 1):S40-S59.

5. Pringsheim T, Davenport W, Mackie G, et al. Canadian headache society guideline for migraine prophylaxis. Can J Neurol Sci. 2012; 39(2 Suppl. 2):S1-59.

6. Holroyd KA, O'Donnell FJ, Carlson BW, et al. Effect of preventive (beta blocker) treatment, behavioural migraine management, or their combination on outcomes of optimized acute treatment in frequent migraine: randomized controlled trial. BMJ. 2010; 341:c4871.

7. Holland S, Silberstein SD, Freitag $F$, et al. Evidence-based guideline update: NSAIDs and other complementary treatments for episodic migraine prevention in adults: report of the Quality Standards Subcommittee of the American Academy of Neurology and the American Headache Society. Neurology. 2012; 78(17):1346-53.

8. Rockett FC, de Oliveira VR, Castro K, et al. Dietary aspects of migraine trigger factors. Nutr
Rev. 2012; 70(6):337-56

9. Stovner $\mathrm{Lj}$, Hagen $\mathrm{K}$, Jensen $\mathrm{R}$, et al. The global burden of headache: a documentation of headache prevalence and disability worldwide. Cephalalgia 2007; 27(3):193-210.

10. Steiner TJ, Stovner LJ, Al Jumah M, et al. Improving quality in population surveys of headache prevalence, burden and cost: key methodological considerations. J Headache Pain. 2013; 14:87.

11. Katsarava Z, Kukava M, Mirvelashvili E, et al. A pilot methodological validation study for a population-based survey of the prevalences of migraine, tension-type headache and chronic daily headache in the country of Georgia. J Headache Pain 2007; 8:77-82

12. Rao GN, Kulkarni GB, Gururaj G, et al. The burden of headache disorders in India: methodology and questionnaire validation for a community-based survey in Karnataka State. J Headache Pain 2012; 13(7):543-50.

13. Yu SY, Cao XT, Zhao G, et al. The burden of headache in China: validation of diagnostic questionnaire for a population-based survey. J Headache Pain 2011; 12(2):141-6.

14. Linde M, Gustavsson A, Stovner LJ, et al. The cost of headache disorders in Europe: the Eurolight project. Eur J Neurol 2012; 19(5):703-11.

15. Headache Classification Committee of the International Headache society. The international classification of headache disorders, 3rd edition (beta version). Cephalalgia 2013;33(9):629-808.

16. Stovner LJ, Al Jumah M, Birbeck GL, et al. The methodology of population surveys of headache prevalence, burden and cost: principles and recommendations from the Global Campaign against Headache. J Headache Pain 2014; 15:5.

17. Lampl C, Steiner TJ, Mueller T, et al. Will (or can) people pay for headache care in a poor country? J Headache Pain 2012; 13(1):67-74.

18. Hu XH, Markson LE, Lipton RB, et al. Burden of migraine in the United States. Disability and economic costs. Arch Intern Med 1999; 159 (8):813-8.

19. Bigal ME, Rapoport AM. Obesity and chronic daily headache. Curr Pain Headache Rep 2012; 16 (1):101-9.

20. Yu S, Liu R, Zhao G, et al. The prevalence and burden of primary headaches in China: a 
population-based door-to-door survey. Headache 2012; 52(4):582-91.

21. Kafeel H, Rukh R. Prevalence Of Headache In
General Population Of Karachi, Pakistan. J. App Pharm 2014;6(3):308-13.

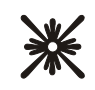

AUTHOR AFFILIATION:

Dr. Santosh Kumar

Associate Professor, Department of Medicine

Liaquat University of Medical \& Health Sciences

(LUMHS), Jamshoro, Sindh-Pakistan.

Dr. Shafaq Nazia

Registrar, Department of Medicine

LUMHS, Jamshoro, Sindh-Pakistan.

Dr. Suhail Ahmed Almani (Corresponding Author)

Porfessor, Department of Medicine

LUMHS, Jamshoro, Sindh-Pakistan.

Email: saalmani123@yahoo.com

Dr. Manzoor Lakhair

Associate Professor, Department of Neurology

LUMHS, Jamshoro, Sindh-Pakistan.

Dr. Muhammad Iqbal Shah

Associate Professor, Department of Medicine

LUMHS, Jamshoro, Sindh-Pakistan.

Dr. Zubair Suhai

Department of Medicine

LUMHS, Jamshoro, Sindh-Pakistan. 